\title{
NOTAS
}

\section{ALFONSO DE CARTAGENA: SUS OBSERVACIONES SOBRE LA LENGUA}

En 1454 Alfonso de Cartagena, obispo de Burgos, escribió una obra titulada Oracional de Fernán Pérez de Guzmán. Abrumado por la soledad y las tribulaciones, Pérez de Guzmán había escrito al obispo en busca de consuelo. Cartagena acudió en su ayuda con este tratado sobre la oración, en cincuenta y siete capítulos con prólogo y "ultílogo"1. Aunque la obra merece un estudio detallado de sus ideas y de sus fuentes teológicas y literarias, me limitaré a estudiar ahora las observaciones del autor sobre la lengua española. En el Oracional se encuentran esparcidos diversos comentarios sobre palabras y giros, sobre su uso y su etimología. La importancia de tales observaciones salta a la vista si se tiene en cuenta que fueron escritas casi medio siglo antes de que Nebrija publicara su Gramática de la lengua castellana y unos ochenta años antes del Diálogo de la lengua de Juan de Valdés. Desde luego, hay que reconocer que el Oracional difiere de esas obras posteriores en que su interés por el lenguaje es secundario. Aún no había llegado el momento oportuno para una obra dedicada completa y exclusivamente a un idioma moderno. Sin embargo, el obispo de Burgos merece ser estudiado como precursor de los filólogos del Renacimiento.

Las notas de Cartagena sobre la lengua se deben a su deseo de claridad. La busca de la precisión lo llevó a cierta verbosidad, que se nos antoja más divertida que pesada. El autor mismo se dió cuenta de tal propensión y la justificó diciendo que, "guardada la verdad dela sciencia, bueno e prouechoso es habundar de palabras por donde mejor lo entienda quien lo oyere" (cap. 18) ${ }^{2}$. Pero su verbosidad no se debe a un afán de amontonar palabras o de ostentar erudición. Introduce sus referencias y citas lingüísticas conscientemente, a fin de aclarar en lo posible sus explicaciones teológicas, "por que quando por muchas cosas se dize vn vocablo non se cognosce así tan clara mente la diferencia dellas commo quando cada cosa tiene vocablo apartado por sí. Por ende, en quanto fazer se puede, es prouechoso dar vocablos a cada cosa, por que mejor se cog-

1 El prólogo y un fragmento del primer capítulo fueron publicados por F. LóPEz Estrada, "La retórica en las Generaciones y semblanzas de Fernán Pérez de Guzmán", RFE, 30 (1946), 341-345.

2 Todas las citas son de la edición de Murcia, 1485 (B. N. M., signatura actual I-659). El Oracional figura además en un ms. del siglo xv (B. N. M., ms. 9156). He conservado la ortografía original, aunque supliendo la puntuación, la acentuación, las mayúsculas y la cedilla ante $-a$ y $-o$ donde hace falta. 
nosca qué es delo que home fabla" (cap. 8). Corolario de ese deseo de claridad es la insistencia en el empleo correcto de los vocablos y giros. A menudo aparecen expresiones como: "para más clara mente entender esto", "la estrecha significación", "propria mente fablando", "estrecha mente tomado el nombre", "para cognoscer bien la propriedad dello", y sobre todo "es fablar inproprio". Estos dos puntos, claridad y buen uso, forman la base de casi todas sus observaciones lingüísticas.

Por lo común, el método de Cartagena consiste en discutir los diversos significados de una sola palabra, o bien en apuntar las diferencias y matices de una pareja o serie de vocablos. Ejemplo de lo primero es la explicación inicial de la palabra oración. El autor menciona su uso gramatical: "qualquier proposición o fabla que entera significación tenga"; particulariza su sentido en la retórica: "la fabla solempne que alas vezes a príncipes o a pueblos e avn a amigos se face, commo fizieron Demónstenes e Tullio e otros innumerábiles oradores delos siglos antiguos, así griegos commo latinos, e fazen oy los eloqüentes modernos" (cap. 1); y por último llega a su valor religioso: la elocuencia sagrada de los Padres de la Iglesia y otros santos, que es el sentido de la palabra que a él le interesa. De modo semejante se esfuerza por concretar términos abstractos como creer, al cual asigna (cap. 3) cuatro grados de intensidad ( $d u b d a$, sospecha, opinión y sciencia), y sabio, que debe aplicarse sólo al que posee las virtudes intelectuales (inteligencia, ciencia, sapiencia, arte y prudencia o discreción), "avn que en algunas partes non se guarda así, ca llaman sabios a los juristas, mas non es proprio fablar. Ca deuen añader sabio en derecho" (cap. 8). Con igual discernimiento discute los usos de términos no abstractos, como traer: "En nuestro lenguaje dezimos traher por diuersas cosas. Ca diremos «aquel trahe dos arouas», "aquel trahe mucha gente», mas cierto es que el traher delas arouas e el traher dela gente non es vna manera de traher. Ca el traher delas arouas es en tener las acuestas, e el traher dela gente es en guiar la e que lo siguan" (cap. 18).

Con el segundo método, Cartagena escudriña la serie de vocablos que significan grados sucesivos de respeto y sumisión: latria, hyperdulia, dulia, subdulia y cortesia. Aunque la explicación de estos términos interese más al teólogo que al estudioso de la lengua, vale la pena notar que el autor emplea hyperdulia para indicar la reverencia debida a todos los santos (no sólo a la Virgen) y hasta a hombres píos que aún viven. Dulia, para él, no indica sino el respeto debido a una persona de posición social más alta.

De bastante interés es su opinión sobre el empleo correcto de facción/acción y fazer/hazer (cap. 7):

Aquello propria mente se llama facción que faze su acto fuera del home, commo edificar e otros actos, quier sean sotiles quier groseros. E acción propria mente se llama aquella que exersce sus actos de dentro del home, commo disponer sus passiones e quietar e pacificar su coraçón... $\mathrm{E}$ avn que en nuestro común fablar todo lo mesclamos en vno, e nunca o pocas vezes vistes fazer diferencia entre estos vocablos fazer e hazer, pero la estrecha significación dellos grand diferencia trahe.

$\mathrm{Si}$ otros escritores del siglo $\mathrm{xv}$ se contentaban con emplear una forma $\mathrm{u}$ 
otra, o bien las dos ${ }^{3}$, Cartagena trata de explicar la coexistencia de fazer y hazer diferenciándolas semántica y ortográficamente, lo cual parece indicar que ignoraba el desarrollo fonético que había dado lugar a esa pareja ${ }^{4}$. El hecho de que existiera facción < factionem, de facere, y acción < actionem, de agere, habrá inflüldo en esa diferenciación.

Veamos las observaciones del autor sobre la serie verdad, veridicidad y veracidad: "La verdad es por respecto a la cosa mesma" (esto es, la norma absoluta), "veridicidad es fablar verdad", "veracidad es obrar verdad" (cap. 21). De las tres formas sólo verdad y veracidad existen en el castellano actual, y el significado que Cartagena atribuye a veridicidad corresponde al de veracidad. También se detiene en la pareja gradescimiento y gracia; ésta se refiere a la virtud, dependiente de la justicia, pero como la palabra se empleaba también para indicar una dádiva o un favor ${ }^{5}$, Cartagena prefiere el vocablo más largo. Afabilidad, amistad y anuticia [sic, por amicitia] se estudian de modo semejante. La primera es la palabra justa; las otras dos son sinónimos más o menos aceptables. Lo mismo cabe decir de liberalidad y sus equivalentes más populares, largueza y franqueza.

Sobresale en este género el pasaje relativo al Padre Nuestro. Según Cartagena, la primera línea debe traducirse al castellano "Pater noster que eres en los cielos":

E non dezimos estás, mas eres, que propria mente fablando el estar non es el ser, mas cierta qualidad dél, por que al ser ponemos tres maneras. Dezíen ya ser quando es el omne tendido, asentar quando es coruo e las piernas encoǵidos [sic] en algund vanco, e estar quando es leuantado e tiene sus miembros vno sobre otro segund la orden deuida, e estas diferencias e qualidades non conuienen a Dios.

Por lo tanto, debe decirse eres, "pero fablando llana e general mente dezimos estás, non refriendo [sic] nuestra intención a qualidad alguna del ser, mas ala essencia" (cap. 31). La explicación es significativa en cuanto que constituye uno de los primeros esfuerzos por aclarar esas palabras ${ }^{6}$.

Por otra parte, no siempre juzga Cartagena necesario distinguir entre términos análogos. Dice, por ejemplo que entendimiento y razón son intercambiables, "avn que entre ellas alguna delgada diferencia fazen los que mucho quisieron specular en la philosophía, pero non la solemos fazer acá en el fablar común" (cap. 40).

3 JAmes H. ENgLish, The alternation of $\mathrm{H}$ and $\mathrm{F}$ in old Spanish, New York, 1926, p. 94, dice: "The fifteenth century is a period of great literary development. By this time the phenomenon of $h$ for $f$ is widely spread throughout Spain. Some writers adhere conservatively to the traditional $f$ and spell entirely apart from their pronunciation. Others vacillate in their spelling between $h$ and $f$. Notable among those who spell with both $h$ and $f$ are F. Yñigo de Mendoza, Juan de Mena, Gómez Manrique, Jorge Manrique, Mosén Diego de Valera, Fernando de Rojas (Celestina)".

4 Nebrija, que sí conocía este desarrollo, resolvió el problema eliminando de la ortografía la $h$ latina muda y empleando la letra $h$ para representar la $f$ aspirada. Véase ENGLish, loc. cit.

5 Hacía siglos que gracia tenía varios significados. Véanse, por ejemplo, sus usos en el Poema del Cid, versos $248 b$ y 1936.

6 Nebrija no se ocupa del problema de ser y estar en su Gramática, ni señala diferencia alguna entre ambas formas en su vocabulario castellano-latino. 
Para lograr mayor claridad, Cartagena se sirve también de ejemplos y citas. En las explicaciones de asuntos teológicos o filosóficos generalmente remite a los autores clásicos o a los Padres de la Iglesia; en sus comentarios lingüísticos emplea con frecuencia palabras y frases de la vida diaria. Tal mezcla de elementos eruditos y populares da al Oracional una amena variedad. Así, al mencionar la palabra creer en una discusión profunda sobre la fe, añade gratuitamente que "a aquellos aquien deuemos algo llamamos creedores, por que creyeron que cumpliríamos lo que les prometimos" (cap. 3). Más adelante, al hablar de los grados de la creencia, pone la frase "el rey está en Toledo" para explicar su idea. La frase en sí, dice el obispo, puede ser verdadera o no, pero si viéramos pasar a muchos caballeros dirigiéndose a esa ciudad, nos inclinaríamos a creerla. La misma frase, con "Sevilla" en vez de "Toledo", aparece usada de modo semejante en el capítulo relativo a la verdad. Para ilustrar el sentido de liberalidad y de su sinónimo corriente largueza (definido como "socorrer home a otro con los bienes temporales") el autor usa un ejemplo del habla callejera: "Deste claman a las vezes los harautes, deziendo ¡Largueza, largueza!” (cap. 14). Hablando de dulia, observa que la palabra quiere decir servidumbre, pero que su empleo puede compararse con el de servicio (cap. 17):

E muestra se bien esto por la manera de fablar común mente guardada en Castilla. E quando nos ofrescemos por escripto o por palabra a honrar e complazer a mayor que nos, avn que non tenga sobre nos prelación nin jurisdición alguna, vsamos desta palabra seruiscio diziendo que le seruiremos e somos prestos a su seruiscio e semejantes palabras que retornan en seruir... e es modo de fablar cortés e loable.

Cabe mencionar aquí que el autor presenta dos sustitutos para fablar, señalando sus usos particulares: "Ca boquear o parlar común mente se suele dezir por el fablar excessiuo e non tan bueno e distincto commo deuía ser, quier enla significación delas palabras, quier enla non buena expressión dela lengua" (cap. 26). En su ya citado comentario del Padre Nuestro menciona la frase vulgar "aquél come pan de fulano" para mostrar que pan significa todo lo necesario para nuestro mantenimiento (cap. 32). La familiaridad de Cartagena con los tribunales se revela en el ejemplo que escogió para aclarar el prefijo re-: "Ca lo muchas vezes visto llamamos reuisto, commo se usa en la audiencia real quando los procesos se veen la segund vez llaman reuista" (cap. 15).

A veces don Alfonso une al ejemplo un juicio sobre la propiedad de su uso. Está bien decir que una persona ama el vino o los caballos, pero “avn que algunas uezes burlando se diga que alguno es amigo del vino o es amigo delos juegos, esto dize se por manera de alguna semejança, mas es fablar inproprio" (cap. 5) ${ }^{7}$. También señala algunos neologismos que no le agradan. No se opone a la novedad de tales expresiones, sino a su falta de reverencia (cap. 24):

7 Cf. Alfonso X, Siete partidas, part. IV, tít. 11, ley 13: "E puede ome aver amor ala cosa e non avrá amistad a ella... E así se prueva que non es una cosa amistad e amor: porque amor puede venir de una parte tan solamente: mas la amistad conviene en todas guisas que venga de amos a dos". 
Ya se trahe en costumbre de dezir que vn omne es deuoto a otro si ha voluntad dele complazer o seruir, e esta manera de fablar ami parescer ha poco que entró en Castilla, ca ya veedes muchas vezes dezir, quando quieren espremir grand buena voluntad a alguno, dizen "fulano mucho es vuestro deuoto", e esto creo que aya venido dela vezindad de otras comarcas, ca veemos que algunos príncipes nuestros comarcanos vsan esta manera d'escriuir, deziendo en la supra scripción dela letra "al nuestro deuoto", e de aquí pienso que ha començado esta manera de fablar en Castilla... Ca "voto a Dios" dezir tan amenudo en cada aserción bien sabedes que non se vsaua en este regno quando vos érades de veynte años, e toman lo ya por polideza... Pero a mi parescer, con deuida reuerencia fablando, honesto sería dexar esta palabra por respecto a Dios... ${ }^{8}$

Otro aspecto de los comentarios de Cartagena es su presentación de las etimologías o del parentesco de varias palabras. Desde luego, sus derivaciones no siguen un método científico, pero sí revelan bastante discernimiento en cuanto a la evolución de la lengua. Ejemplo típico es su comentario a la palabra cardinal: "Pero la cabeça e principales dellas [de las virtudes] son las quatro que cardinales se llaman, por que cardinales quiere dezir quicios. E como enel quicio se mueue la puerta, así enellas commo enel quicial dela vida se reueluen todas las mudanças de nuestro bien beuir..." (cap. 10). Se expresa con cierta torpeza, pero su interpretación es exacta cuando dice que "Mas [léase mos] quiere dezir costumbre, e así moral quiere dezir costumbrar..." (cap. 20). Sugiere tres orígenes posibles para la palabra religión (usando vocablos castellanos más bien que latinos en su explicación):

La primera es deziendo religión de releer, commo si dixiésemos lección o relección... La segunda... es que se diga religión commo reelección, que es reescogimiento, e esto se dize segund Augustino lo tañe... La tercera interpretación, que digamos religión commo si dixiésemos religación, que quiere dezir reatamiento, ca ligar es atar e religar es reatar (cap. 15).

Los estudios etimológicos modernos apenas han logrado superar esta explicación ${ }^{9}$. Cartagena cita una fuente latina al hablar del término oración: "Casiodoro dize que oración es oris racion, que quiere dezir razón dela boca. Ca como os quiera dezir boca, ora, que deste vocablo desciende, quiere dezir boquear". Añade, como ya hemos indicado, que boquear "non se suele tomar en buena significación" (cap. 26). No hay sino un paso de oración a adoración, porque ésta "non es ál salvo una muestra exterior dela deuoción e humilldad que está enel coraçón de quien ora, ca la oración verdadera enel coraçón se faze..." (cap. 57). Cartagena deriva devoción de denouer [léase deuouere], y explica que "antigua mente los gentiles llamauan deuotos a aquellos que mucho se

8 Este pasaje fué publicado en parte por J. Amador DE LOS Rfos en su Historia critica de la literatura española, Madrid, $186_{5}$, t. 6, p. 319, nota 3 .

${ }^{-}$A. Ernout et A. Meillet, Dictionnaire étymologique de la langue latine (Paris, 1939), dicen que "le préfixe est re-, red- (cf. relliquae, reliquae); mais le second élément fait difficulté. Cicéron le rattache a relegere... Mais il semble qu'il vaille mieux rattacher religiō à religāre; religiō serait proprement 'le fait de se lier vis-à-vis des dieux...",. 
dauan a los ydolos e posponían su vida por la salud dela hueste o dela república..." (cap. 24).

Cartagena se interesa especialmente por el uso de los prefijos latinos y explica palabras como veniat y adveniat, gradior, ingredior y egredior. A propósito de esos prefijos lamenta las limitaciones del español: "Nuestro romance non lleua bien estas diferencias" (cap. 33). La misma queja se repite más de una vez. Sin embargo, Cartagena se dió cuenta de que el latín tampoco era perfecto y de que tenía sus lagunas: "Para declarar las diferencias dela reuerencia que se deue alos mayores, la lengua latina pocos vocablos puso e avn ésos non eran suyos, ca delos griegos los tomó" (cap. 18). En cuanto a su conocimiento del griego, nada en esta obra nos indica que supiera más que los términos eclesiásticos corrientes, como dulia, latria, etc.

Northwestern University.

KenNeth R. Scholberg

Evanston, Illinois.

\section{UNA CARICATURA DE JUAN RUIZ DE ALARCÓN}

Los entremeses del siglo xvir son en su mayor parte pequeños cuadros de costumbres, cómicos y burlescos, sin más pretensiones que la de provocar a risa al público. Sin embargo, en manos del gran maestro del género, Luis Quiñones de Benavente, no pocas veces las "burlas" se mezclan con las "veras", o sea con la sátira social y moral, sátira que nunca llega a ser violenta: "la reprehensión pára en los vicios, sin llegar nunca a las personas", dice don Manuel Antonio de Vargas en el Prólogo a la Iocoseria $^{1}$. Quiñones tenía fama de ser enemigo de toda maledicencia; en un pasaje tradicionalmente interpretado como alabanza al gran entremesista, dice Tirso:

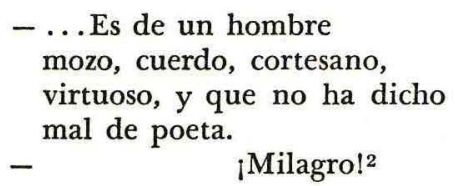

Dada esa fama -enteramente justificada por una lectura de las 142 piezas atribuídas a Quiñones en la Colección de Cotarelo-, nos choca al

1 Iocoseria. Burlas veras, o reprehensión moral y festiua de los desórdenes públicos, en doze entremeses representados $y$ veinte y quatro cantados. Van insertas seis loas $y$ seis Íacaras que los Autores de Comedias han representado y cantado en los teatros desta Corte. Compvestos por Lvis Qviñones DE BenAuente, natural de la Imperial Toledo. Recopilados por D. Manvel Antonio de Vargas. Dirigidos a D. Mario Mastrillo Beltrán, residente de la Sereníssima Archiduquesa Claudia. Con Privilegio. -En Madrid, por Francisco García, año de 1645. A costa de Manuel López, mercader de libros.

2 Tanto es lo de más como lo de menos, II, viI. La fecha de la comedia queda algo dudosa. Cotarelo la cree de 1618-1619 (NBAE, t. 9, p. xxxviii), pero se basa en un dato inexacto; en otro lugar (NBAE, t. 17, p. lxxvi) dice: "1620 lo más tarde". Doña BLANCA DE Los Rfos niega que la alusión sea a Quiñones, y fecha la comedia en 1614 (en su edición de las Obras completas de Tirso, t. 1, Madrid, 1946, pp. 947 ss.). RutH L. KENNEDY, "Studies for the chronology of Tirso's theatre", $H R, 11$ (1943), p. 42, opina que la comedia fué escrita en 1620 y retocada hacia 1623 . 